\title{
The low fresh gas flow anesthesia and hypothermia in neonates undergoing digestive surgeries: a retrospective before- after study
}

Yu Cui ${ }^{1 *+}$ (D) Yu Wang ${ }^{2+}$, Rong Cao ${ }^{1 \dagger}$, Gen $\mathrm{Li}^{3}$, Lingmei Deng ${ }^{1}$ and Jia $\mathrm{Li}^{1}$

\begin{abstract}
Background: Based on the previous investigation in our institution, the incidence of intraoperative hypothermia in neonates was high. Since September 1st, 2019, the recommendation had been launched to utilize $\leq 1 \mathrm{~L} / \mathrm{min}$ fresh gas flow during the neonates' surgical procedure. We therefore intended to evaluate the association between low fresh gas flow anesthesia and the occurrence of hypothermia in neonates undergoing digestive surgeries.

Methods: A retrospective chart review, before-after study was conducted for neonates who underwent digestive surgeries. The primary outcomes were the incidence of hypothermia. The secondary outcomes included hospital mortality, the value of lowest temperature, blood loss, mean body temperature during the surgery, the length of hypothermia during the surgery and postoperative hospital length-of- stay (PLOS).

Results: 249 neonates fulfilled the eligibility criteria. The overall incidence of intraoperative hypothermia was 81.9\%. The low fresh gas flow anesthesia significantly reduced the odds of hypothermia [routine group: 149 (87.6\%) versus low flow group: 55 (69.6\%); $p<0.01$ ]. Moreover, the low fresh gas flow anesthesia could reduce the length of hypothermia [routine group: 104 mins $(50,156)$ versus low flow group: 30 mins $(0,100) ; p<0.01$ ], as well as elevate the value of lowest temperature for neonates [routine group: $35.1^{\circ} \mathrm{C}(34.5,35.7)$ versus low flow group: $35.7^{\circ} \mathrm{C}(35.3$, 36); $p<0.01$. After adjustment for confounding, low fresh gas flow anesthesia and the length of surgical time were independently associated with intraoperative hypothermia.
\end{abstract}

Conclusions: Low fresh gas flow anesthesia is an effective way to alleviate hypothermia in neonates undergoing open digestive surgery.

Keywords: Low fresh gas flow anesthesia, Neonates, Hypothermia

\footnotetext{
* Correspondence: cuiyu19831001@163.com

†Yu Cui, Yu Wang and Rong Cao contributed equally to this work.

'Department of Anesthesiology, The Affiliated Hospital, School of Medicine,

UESTC Chengdu Women's \& Children's Central Hospital, No.1617, Riyue

Avenue, Qingyang District, Chengdu 610091, PR China

Full list of author information is available at the end of the article
}

(c) The Author(s). 2020 Open Access This article is licensed under a Creative Commons Attribution 4.0 International License, which permits use, sharing, adaptation, distribution and reproduction in any medium or format, as long as you give appropriate credit to the original author(s) and the source, provide a link to the Creative Commons licence, and indicate if changes were made. The images or other third party material in this article are included in the article's Creative Commons licence, unless indicated otherwise in a credit line to the material. If material is not included in the article's Creative Commons licence and your intended use is not permitted by statutory regulation or exceeds the permitted use, you will need to obtain permission directly from the copyright holder. To view a copy of this licence, visit http://creativecommons.org/licenses/by/4.0/ The Creative Commons Public Domain Dedication waiver (http://creativecommons.org/publicdomain/zero/1.0/) applies to the data made available in this article, unless otherwise stated in a credit line to the data. 


\section{Background}

Intraoperative hypothermia that is defined as core temperature $<36.0^{\circ} \mathrm{C}$ is one of complications faced by anesthesiologists during surgical period, which may exposure patients to acidosis, imbalanced oxygen consumption, delayed anesthesia recovery, coagulopathy, wound infections and bleeding [1,2]. Available literature has proved that intraoperative hypothermia is an independent risk factor of early perioperative complications and mortality [3].

Among various surgeries, the occurrence of intraoperative hypothermia is high in digestive surgeries due to visceral and peritoneal surface exposure, anesthetic-induced impairment of thermoregulatory control and requirement of intestinal irrigation fluid. Lai et al. reported that patients' age is one of main factors contributed to inadvertent intraoperative hypothermia, and the overall incidence is as high as $83.3 \%$ in neonates despite the passive and active temperature management have been conducted [4]. Some congenital intestinal disorders in neonates need urgent surgical intervention, i.e., necrotizing enterocolitis, meconium ileus, and congenital intestinal atresia. This is indeed a challenge for anesthesia providers and scrub nurses because normothermia is hard to be maintained on neonates undergoing digestive surgeries. Compared to adults, the neonates are more susceptible to develop hypothermia since the mechanism of thermoregulation has not yet been well established. This problem is amplified by inadequately warmed operating room and fluid infusion. With increasing awareness of intraoperative hypothermia, emerging evidence has proposed various methods to maintain normothermia [5], while the effectiveness strategies on neonates are limited.

Previous study had demonstrated that low-flow anesthesia technique was accepted by some anesthesiologists due to heat and humidity preservation, as well as decreased gas consumption [6]. Kleemann et al. found that the temperature of inspired gas during low-flow anesthesia was higher when compared to high-flow anesthesia, indicating heat could be well reserved by low-flow anesthesia [7]. However, that low fresh gas flow in sevoflurane anesthesia led to compound A generation was an issue worried by some anesthesia providers, since compound A had a dose-related nephrotoxicity which had been confirmed in laboratory test [8]. Even in the developed country, the target of fresh gas flow was $2 \mathrm{~L} /$ min for sevoflurane anesthesia [9]. Some anesthesia providers were reluctant to further reduce fresh gas flow during sevoflurane administration and utilized more than $1 \mathrm{~L} / \mathrm{min}$ fresh gas flow to achieve desired anesthesia in clinical practice. In fact, as early as in 2000, Obata and colleagues had confirmed that prolonged low-flow sevoflurane anesthesia had the same effects on renal and hepatic functions as high-flow sevoflurane [10].
Based on the previous investigation in our institution, although the active temperature managements had been implemented, such as cotton blankets, mattress, and infusion fluid warming, the incidence of hypothermia in neonates reached up to $90 \%$. To reduce the incidence of hypothermia in neonates, we hypothesized that low fresh gas flow anesthesia was a good way to keep normothermia in neonates. In our institution, till August 2019, the fresh gas flow to perform neonate's anesthesia relied on the practitioner's experience and opinion, and it might exceed $1 \mathrm{~L} / \mathrm{min}$. Since September 1st, 2019, the new recommendation had been launched to utilize $\leq 1 \mathrm{~L} / \mathrm{min}$ fresh gas flow during the neonates' surgical procedure. Therefore, we intended to evaluate the association of low fresh gas flow anesthesia with the occurrence of intraoperative hypothermia in neonates undergoing digestive surgeries.

\section{Methods}

After obtaining Institutional Review Board (IRB) approval [No. 2020(3)], we retrieved patient data from the electrical record system at Chengdu Women's and Children's Central Hospital between June 31, 2018 (from the very beginning of electrical medical record utilization) and April 1, 2020. This study had been registered at http://www.chictr.org.cn/index.aspx with No. ChiCTR2000034242 on June 27, 2020. The necessity of informed consents was waived by the IRB, considering the nature of the retrospective study and the anonymized patient data.

\section{Study population}

The inclusion criteria were neonates who were underwent digestive surgeries. The exclusion criteria include as follows: 1. Conversion from laparoscopic surgery to open surgeries; 2. Lacking documentation of temperature; 3. Congenital heart disease patients with clinical symptoms; 4. Digestive surgery were performed concurrently with other procedures.

\section{Data collection}

Once the list of the patients was created, the following variables were collected from our electronic patient registration system, i.e., age at surgery, weight at surgery, sex, birth body weight, gestational days, ASA status, comorbidities, the length of surgical time, mean body temperature during the surgery, intraoperative flow of fresh gas, estimated blood loss, blood transfusion, plasma transfusion, fluid infusion during surgery, preoperative hemoglobin, postoperative hemoglobin, the duration of hypothermia, the lowest temperature, postoperative hospital length-of-stay (PLOS) and intraoperative urinary volume. Neonates were defined as patients under the age of 28 days. Mortality data was obtained 
from a combination of hospital discharge disposition, our death records and the legal guardian or power of attorney who withdrew treatment in the patients with endotracheal tube. Actual PLOS was from surgical date to discharge date. The duration of hypothermia was calculated from the beginning of hypothermia to the beginning of normothermia. As the rule in our institution, only anesthesia providers with 5 years' experience were authorized to perform anesthesia in neonates. Since we had strict standard operative procedure guidelines, the strategies for avoiding hypothermia in our institution, included utilizing anesthesia station with heat and humidity exchanger, warm air circulation, warm infusion fluids, and warm mattress pads and blankets. Forced air warming was routinely used before and after the change in fresh gas flow practice. The temperature of the operating room was usually controlled between $22.0^{\circ} \mathrm{C}$ and $24.0^{\circ} \mathrm{C}$. Dräger Primus anesthesia workstation with a heat and moisture exchanger was used for neonates. According to the description in background section, we therefore looked at the results from the patients that were underwent surgery before (Routine group) and after September 2019 (Low flow group).

\section{Intraoperative esophageal temperature}

For neonates undergoing surgery under general anesthesia in our institution, an esophageal probe was inserted into esophagus after general anesthesia. Body temperature was automatically recorded at 10 -min intervals until the patients left the operating room. Based on definition from several previous studies $[1,2]$, hypothermia was defined as body temperature $<36.0^{\circ} \mathrm{C}$ and normothermia was considered as $36.0^{\circ} \mathrm{C} \leq$ body temperature $\leq 37.4^{\circ} \mathrm{C}$. When $<36.0^{\circ} \mathrm{C}$ was recorded on the electronic record, the patient was considered to have hypothermia. Intraoperative mean body temperature was defined as the sum of recorded body temperature divided by the total times. The esophageal probe was removed immediately before the patient left the operating room.

\section{Outcome measures}

The primary outcome was the incidence of intraoperative hypothermia.

The secondary outcomes included.

1. hospital mortality,

2. the value of lowest temperature,

3. blood loss,

4. mean body temperature during the surgery,

5. the length of hypothermia during the surgery,

6. postoperative hospital length-of-stay (PLOS).

\section{Statistical analysis}

The sample size was calculated based on the previous study done by Lo et al. [11] To detect a change in temperature of $0.5{ }^{\circ} \mathrm{C}$ with a study power of $90 \%$ and an alpha error of $5 \%$ the sample size required was 54 . Considering $20 \%$ dropout because of lacking documentation of temperature, we recruited 65 patients in each group at least. The categorical variables were expressed as percentages. Continuous variables are presented as the mean \pm standard deviation [SD] or median and interquartile range [IQR] (25-75\%) if nonnormally distributed. The student $t$ test was used to compare normally distribute data, otherwise the Mann Whitney U-test was used to compare two groups. The chi-squared test was used for categorical data. Multivariable logistic regressions were performed to determine the association between potential confounding variables and occurrence of intraoperative hypothermia. To adjust for confounding, analysis was performed using clinically relevant, the variables was selected in advance, including age, sex, weight at surgery, birth body weight, gestation days, the length of surgical time and fresh gas flow rate. These clinically relevant variables were selected based on biologic plausibility and were the most popular reported confounders in cohort on neonates [12]. Variance inflation factors for all predictors in multivariable regression were chosen to 1.0. Patients lacking documentation of temperature was excluded from the study. The analyses were carried out with $\mathrm{R}$ studio 3.5.2. The main $\mathrm{R}$ packages were listed in the additional file $1 . P<0.05$ was statistically significant, and all tests were two-sided.

\section{Results}

A total of 315 neonates were identified as having digestive surgeries during the study period. Of this group, 66 neonates were excluded from the study as lacking documentation of intraoperative temperature. After screening for inclusion and exclusion criteria, 249 patients enrolled in this retrospective study, including 170 who underwent routine fresh gas flow anesthesia group (routine group) and 79 in the low fresh gas flow anesthesia group (low flow group). All the patients underwent general anesthesia with tracheal intubation. (Fig. 1).

\section{Patient and clinical characteristics}

Demographics data for both groups were presented in Table 1 . The neonates in the two groups were demographically similar with the routine group composed of 98 boys $(57.6 \%)$ and low flow group 50 boys $(63.3 \%)$. At the time of surgery, body weight $[2.7 \mathrm{~kg}(2.1,3.2)$ in routine group and $2.9 \mathrm{~kg}(2.4,3.2)$ in low flow group] and age $[6$ days $(4,13)$ in routine group and 6 days $(3,9)$ in low flow group] were comparable between two groups. There was no statistically significant difference detected 


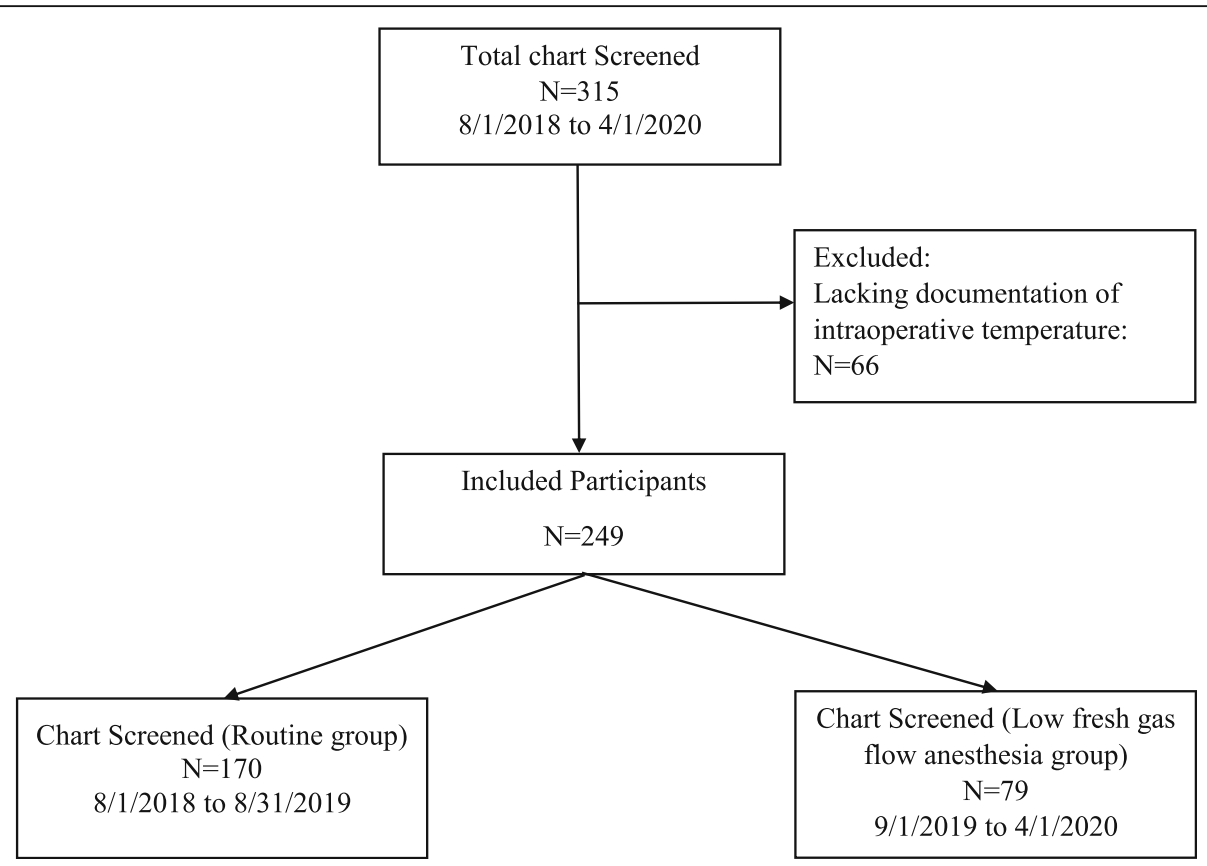

Fig. 1 Study patient flow diagram

between two groups with respect to gestation days, birth weight, ASA status, type of surgery, diagnosis, and surgical service.

\section{Primary and secondary outcomes}

Primary and secondary outcomes were reported in Table 2. In intraoperative period, the duration of surgery, blood loss, fluid infusion and pre-/post hemoglobin were comparable in both groups (Table 2). The overall incidence of hypothermia was $81.9 \%$. Of the 249 patients in the cohort, the hypothermia occurred in 149 of 170 neonates $(87.6 \%)$ allocated to routine group and in 55 of 79 neonates (69.6\%) allocated to low flow group. The low fresh gas flow significantly reduced the odds of hypothermia [routine group: 149 (87.6\%) versus low flow group: 55 (69.6\%); $p<0.01)$ and elevated the intraoperative mean temperature [routine group: $35.6 \pm$ $0.8^{\circ} \mathrm{C}$ versus low flow group: $36.0 \pm 0.6^{\circ} \mathrm{C} ; p<0.01$ ) (Table 2, Fig. 2). Moreover, low fresh gas flow could reduce the length of hypothermia [routine group: 104 mins $(50,156)$ versus low flow group: 30 mins $(0,100)$; $p<0.01]$, as well as elevate the value of lowest temperature for neonates [routine group: $35.1{ }^{\circ} \mathrm{C}(34.5$, $35.7)$ versus low flow group: $\left.35.7{ }^{\circ} \mathrm{C}(35.3,36) ; p<0.01\right]$ (Table 2). No episodes of hypoxia or cardiac arrest were founded in our patients intraoperatively.

\section{Factors associated with intraoperative hypothermia}

Multivariable logistic regression was performed using the presence of intraoperative hypothermia as the dependent variable (Table 3). This complete case analysis included 249 neonates. Among the pre-chosen predictors, the length of surgical time (adjusted odds ratio, 1.01[95\% CI, 1.00 to 1.02$] ; p=0.025)$ and fresh gas flow (adjusted odds ratio, 3.04 [95\% CI, 1.45 to 6.39]; $p=0.003$ ) were independently associated with the occurrence of intraoperative hypothermia.

\section{Discussion}

In our study, low fresh gas flow anesthesia $(\leq 1 \mathrm{~L} / \mathrm{min})$ for the neonates undergoing digestive surgery was associated to reduce the incidence of hypothermia. This method could shorten the length of hypothermia, as well as help to alleviate further decreasing of body temperature. Moreover, by multivariable logistic regression performed, we found that low fresh gas flow anesthesia and the length of surgical time were significantly associated with intraoperative hypothermia.

In this study, intraoperative hypothermia was defined as a core temperature (nasopharyngeal temperature) < $36^{\circ} \mathrm{C}$, in accordance with the definition of the National guideline in UK [13]. The overall incidence of hypothermia was about $81.9 \%$ in our study, which was like the result $(83.3 \%)$ from a study by Lai [4]. Lai et al. also pointed that the incidence of hypothermia was higher in neonates, compared with infants, toddlers and children [4]. From above evidence, we confirmed that compared to other population, neonates had a faster body heat loss during the intraoperative period due to their physiological characteristics. To our knowledge, hypothermia should be prevented rather than treated after its occurrence. With the increasing awareness of 
Table 1 Baseline demographic characteristics of each group

\begin{tabular}{|c|c|c|c|c|}
\hline & Overall patients $(n=249)$ & $\begin{array}{l}\text { Routine } \\
(n=170)\end{array}$ & Low flow $(n=79)$ & $P$ value \\
\hline Age at surgery (days) (Median, IQR) & $6.0(4.0,11.0)$ & $6.0(4.0,13.0)$ & $6.0(3.0,9.0)$ & 0.35 \\
\hline Weight at surgery (kg) (Median, IQR) & $2.8(2.2,3.2)$ & $2.7(2.1,3.2)$ & $2.9(2.4,3.2)$ & 0.27 \\
\hline Sex (male, \%) & $148(59.4)$ & $98(57.6)$ & $50(63.3)$ & 0.48 \\
\hline Birth body weight (kg) (Median, IQR) & $2.8(2.1,3.3)$ & $2.8(2.1,3.3)$ & $2.9(2.2,3.4)$ & 0.20 \\
\hline Gestation days (Median, IQR) & $264(245,274)$ & $263(242,274)$ & $265(248,274)$ & 0.83 \\
\hline ASA, n (\%) & & & & 0.20 \\
\hline । & $1(0.4)$ & $0(0)$ & $1(1.3)$ & \\
\hline$\|$ & $70(28.1)$ & $49(28.8)$ & $21(26.6)$ & \\
\hline III & $159(63.9)$ & $111(65.3)$ & $48(60.8)$ & \\
\hline IV & $19(7.6)$ & $10(5.9)$ & $9(11.4)$ & \\
\hline Type of surgery & & & & 0.38 \\
\hline Elective, n (\%) & 77 (30.9) & $56(32.9)$ & $21(26.6)$ & \\
\hline Emergency, n (\%) & $172(69.1)$ & $114(67.1)$ & $58(73.4)$ & \\
\hline Diagnosis & & & & 0.11 \\
\hline Congenital anorectal malformation, $\mathrm{n}(\%)$ & $51(20.5)$ & $30(17.6)$ & $21(26.6)$ & \\
\hline Gastric perforation, n (\%) & $9(3.6)$ & $5(2.9)$ & $4(5.1)$ & \\
\hline Ileus, n (\%) & $10(4.0)$ & $7(4.1)$ & $3(3.8)$ & \\
\hline Intestinal atresia, n (\%) & $37(14.9)$ & $23(13.5)$ & $14(17.7)$ & \\
\hline Neonatal necrotizing enterocolitis (NEC), n (\%) & $117(47.0)$ & $90(52.9)$ & $27(34.2)$ & \\
\hline Pyloric hypertrophy, n (\%) & $5(2.0)$ & $2(1.2)$ & $3(3.8)$ & \\
\hline Umbilical bulge, $n(\%)$ & $9(3.6)$ & $6(3.5)$ & $3(3.8)$ & \\
\hline Hernia, n (\%) & $1(0.4)$ & $1(0.6)$ & $0(0)$ & \\
\hline Diaphragmatic hernia, n (\%) & $3(1.2)$ & $2(1.2)$ & $1(1.3)$ & \\
\hline Appendicitis, n (\%) & $1(0.4)$ & $1(0.6)$ & $0(0)$ & \\
\hline Intestinal malrotation, n (\%) & $3(1.2)$ & $3(1.8)$ & $0(0)$ & \\
\hline Others, n (\%) & $3(1.2)$ & $0(0)$ & 3 & \\
\hline Surgical service & & & & 0.08 \\
\hline Anoplasty, n (\%) & $51(20.5)$ & $30(17.6)$ & $21(26.6)$ & \\
\hline Enterectomy, n (\%) & $164(65.9)$ & $120(70.6)$ & $44(55.7)$ & \\
\hline Gastric perforation repair, n (\%) & 9 (3.6) & $5(2.9)$ & $4(5.1)$ & \\
\hline Pyloric myotomy, n (\%) & $5(2.0)$ & $2(1.2)$ & $3(3.8)$ & \\
\hline Umbilical bulge repair, n (\%) & $9(3.6)$ & $6(3.5)$ & $3(3.8)$ & \\
\hline Hernia repair, n (\%) & $1(0.4)$ & $1(0.6)$ & $0(0)$ & \\
\hline Others, n (\%) & $10(4.0)$ & $6(3.5)$ & $4(5.1)$ & \\
\hline
\end{tabular}

the harms of intraoperative hypothermia, many ways had been proposed to prevent it from happening. In our institution, the strategies for avoiding hypothermia included utilizing anesthesia station with heat and humidity exchanger, warm air circulation, warm infusion fluids, and warm mattress pads and blankets, but the incidence of hypothermia was still high before September 2019 (87.6\%), which indicated the available strategies were not enough. To date, some anesthesia providers attributed it to patients' age, weight and different surgical procedures. Actually, in 2017, Engorn et al. did a retrospective research in neonates and revealed that gestation days, weight, type of surgery, sex, and length of surgery were not the risk factors for hypothermia except the thermoregulation interventions, which pointed that active and passive warming strategies played the pivotal role in maintaining normothermia [12]. A study with multiple logistic regression in Thailand showed that the following risk factors for core hypothermia included high ASA physical status and open surgery. Significant 
Table 2 Intraoperative and postoperative data

\begin{tabular}{|c|c|c|c|c|}
\hline & Overall patients $(n=249)$ & Routine $(n=170)$ & Low flow $(n=79)$ & $P$ value \\
\hline Fresh gas flow rate (L/min) (Median, IQR) & $2.0(1.0,2.0)$ & $2.0(2.0,2.0)$ & $1.0(1.0,1.0)$ & $<0.01^{*}$ \\
\hline Mean temperature during surgery (Mean \pm SD) & $35.7 \pm 0.8$ & $35.6 \pm 0.8$ & $36.0 \pm 0.6$ & $<0.01^{*}$ \\
\hline Hospital mortality, n (\%) & $25(10.0)$ & $20(11.8)$ & $6(7.6)$ & 0.43 \\
\hline Hypothermia, n (\%) & $204(81.9)$ & $149(87.6)$ & $55(69.6)$ & $<0.01^{*}$ \\
\hline Length of hypothermia (mins) (Median, IQR) & $90(20,148)$ & $104(50,156)$ & $30(0,100)$ & $<0.01^{*}$ \\
\hline The lowest temperature $\left({ }^{\circ} \mathrm{C}\right)$ (Median, IQR) & $35.4(34.7,35.8)$ & $35.1(34.5,35.7)$ & $35.7(35.3,36.0)$ & $<0.01^{*}$ \\
\hline Duration of surgery (mins) (Mean $\pm S D$ ) & $92.0 \pm 45.0$ & $91.8 \pm 45.9$ & $92.6 \pm 43.4$ & 0.81 \\
\hline \multicolumn{5}{|l|}{ Transfusion (ml) } \\
\hline Blood (Mean \pm SD) & $7.1 \pm 12.7$ & $7.7 \pm 13.8$ & $5.7 \pm 10.4$ & 0.52 \\
\hline Plasma (Mean \pm SD) & $0.9 \pm 1.8$ & $1.4 \pm 2.7$ & $0 \pm 0$ & 0.17 \\
\hline Blood loss during surgery $(\mathrm{ml})($ Mean \pm SD) & $4.4 \pm 4.0$ & $4.3 \pm 4.0$ & $4.4 \pm 4.1$ & 0.94 \\
\hline Fluid infusion during surgery $(\mathrm{mL})($ Mean $\pm \mathrm{SD})$ & $98.9 \pm 50.8$ & $99.9 \pm 53.4$ & $97.1 \pm 44.8$ & 0.72 \\
\hline Urine $(\mathrm{ml})($ Mean $\pm \mathrm{SD})$ & $13.6 \pm 11.0$ & $13.2 \pm 10.4$ & $14.3 \pm 12.2$ & 0.85 \\
\hline Preoperative Hemoglobin (g/dL) (Mean \pm SD) & $146.3 \pm 47.2$ & $141.4 \pm 41.3$ & $156.9 \pm 60.0$ & 0.39 \\
\hline Postoperative Hemoglobin (g/dL) (Mean \pm SD) & $125.4 \pm 34.2$ & $124.8 \pm 35.5$ & $126.7 \pm 31.2$ & 0.30 \\
\hline Postoperative hospital length-of- stay (PLOS), days (Mean \pm SD) & $22.9 \pm 18.6$ & $23.9 \pm 19.6$ & $20.8 \pm 16.6$ & 0.13 \\
\hline
\end{tabular}

Note: Sample (n), Standard deviation (SD), Interquartile Range (IQR), ${ }^{*} P<0.05$

protective factor against core hypothermia was heavier body weight [14]. In our study, the enrolled patients were neonates who underwent digestive surgeries, all of whom had the above risk factors rather than the protective factor, which demonstrated the importance of this study.

Our study proved that the length of hypothermia in low fresh gas flow ( $\leq 1 \mathrm{~L} / \mathrm{min}$ ) group was less than in routine group and the value of lowest body temperature was higher. As far as we know, inhaled air was warmed and humidified in upper air ways in spontaneous breathing. During mechanical ventilation with tracheal tube, this mechanism was disturbed, and the air was inhaled to lower airway directly without being warmed and humidified. Ventilation with dry and cold gases would lead to a considerable loss of heat from airway. In the Dräger Primus breathing system, to reduce the loss of heat, the exhaled gases moved through the hotplate once before mixing with cold and dry fresh air [15]. In 2011, Castro et al. reported that insertion of a heat and moisture exchanger increased the temperatures of inhaled gas in adults [15]. Moreover, by comparing $1 \mathrm{~L} / \mathrm{min}$ and $3 \mathrm{~L} /$ min fresh gas flow in a Dräger Primus anesthesia workstation, Bicalho et al. revealed that $1 \mathrm{~L} / \mathrm{min}$ fresh gas flow provided better inhaled gas temperature conservation in children [16], which implied that different gas

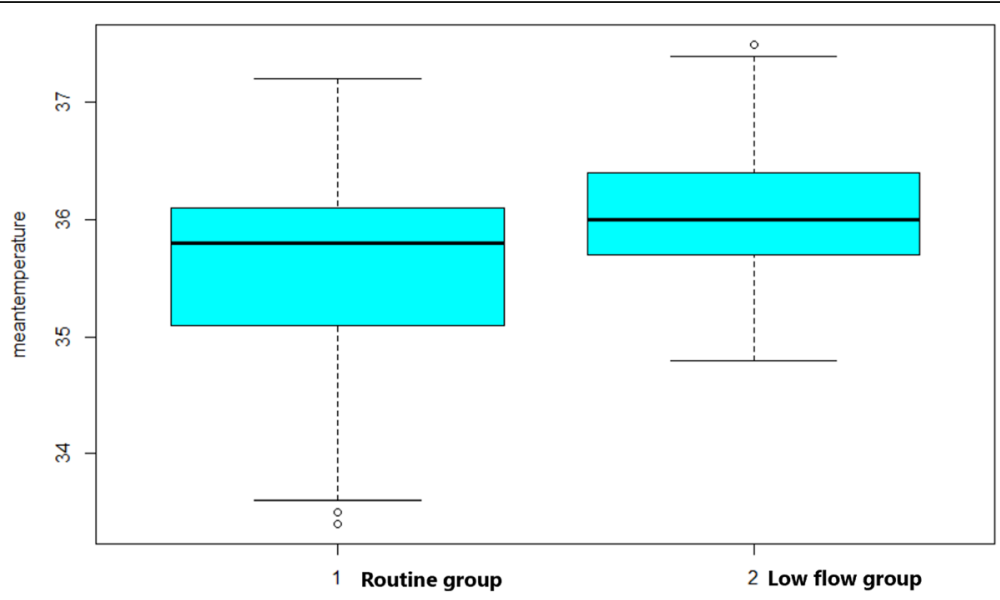

Fig. 2 The meantemperature in Routine group and Low flow group. $1=$ Routine group; 2 = Low flow group 
Table 3 Results of Multivariable Logistic Regression with Occurrence of Intraoperative Hypothermia

\begin{tabular}{llll}
\hline Variable & Adjusted Odds Ratios & $95 \% \mathrm{Cl}$ & $P$ value \\
\hline Age (days) & 0.99 & $0.94,1.05$ & 0.95 \\
Male sex (vs. Female) & 1.11 & $0.54,2.29$ & 0.77 \\
Weight at the surgery time (kg) & 0.52 & $0.09,2.9$ & 0.46 \\
Birth body weight $(\mathrm{kg})$ & 1.42 & $0.26,7.83$ & 0.69 \\
Gestation days (days) & 0.99 & $0.96,1.02$ & 0.56 \\
The length of surgical time (min) & 1.01 & $1,1.02$ & $0.025^{*}$ \\
Fresh gas flow (L/min) & 3.04 & $1.45,6.39$ & $0.003^{*}$ \\
\hline
\end{tabular}

Note: Results of multivariable logistic regression using pre-chosen predictors forced into the model $95 \%$; Confidence Intervals (95\% Cl)

${ }^{*} P<0.05$ is statistically significant

flow was potentially influence body temperature. However, this theory had not been proven in neonates. In our institution, Dräger Primus anesthesia workstation was used for neonates, but the incidence of hypothermia was still high. Two factors might explain the difficulties to sustain normothermia in neonate even though some active and passive tactics had been applied. First, neonates had a large body face ratio, thin skin, low fat content, which was inconducive to temperature preservation. Of course, this problem was compounded by the effects of anesthetic agents that inhibited central thermoregulation by interfering with these hypothalamic reflex responses. Moreover, non-shivering thermogenesis by metabolism of brown fat was limited in premature or critical neonates who were deficient in fat store. Second, the maintenance of body temperature depended on the balance of heat production and loss. According to our results, we had enough evidence to doubt that compared to other resource, the heat loss from respiratory tract due to high fresh gas flow might occupy a large proportion and $1 \mathrm{~L} / \mathrm{min}$ fresh gas flow might be the critical value. The body temperature was hard to be maintained when the fresh gas flow exceeded $1 \mathrm{~L} /$ min since heat loss was beyond production, but this was only our suspicion and further studies were needed to verify it.

Previous studies had revealed that hypothermia was correlated with increased perioperative blood loss and rates of surgical wound infection, which might result in prolonged hospitalization and increased incidence of postoperative adverse events $[17,18]$. In neonates, the literature about the relationship between hypothermia and prognosis was limited. Our study demonstrated that compared to routine group, the value of lowest temperature was higher, and the duration was less in low flow group, which indicated that low fresh gas flow could alleviate the severity of hypothermia. However, we did not find that fresh gas flow had a relationship with PLOS. The result should be interpreted cautiously because of the shortage of medical resources and insufficient economic development in our region. The guardians might withdraw the treatment because of heavy economic burden, which could artificially shorten length of hospital stay. Besides, other potentially relevant clinical outcomes should be examined in our study-like wound infections, but we could not collect the data about wound infections from our electronic patient registration system. Some surgeons might be reluctant to admit the fact that the wound was infected. Thus, the wound infections were not recorded properly in the chart, especially in the patients with mild wound infections.

\section{Limitations}

There were some limitations that should be noted. (1) This was a retrospective study which was at risk of patient selection bias and measurement bias. To reduce the effect of those bias, multivariable regression was conducted to determine the independent association between exposure and outcome. (2) Baseline and preoperative temperature were unknown. When the patients had pre-existed hypothermia, the outcome might be biased. (3) The confidence interval for the "treatment effect" of fresh gas flow was wide, and that a larger sample size would be needed to better delineate the true impact. (4) Because of the shortage of medical resources and insufficient economic development in developing countries like China, most neonates did not have medical-insurance, or the health insurance did not cover newborns. Some critically ill neonates with surgical indications might not be able to receive surgical treatment due to family poverty. Even the patients underwent the surgery, the guardians might withdraw the treatment because of heavy economic burden. In our study, the result of postoperative mortality and PLOS, therefore, might be biased. (5) One potential limitation of the investigation was limited generalizability to other settings.

\section{Conclusions}

In summary, we concluded that low fresh gas flow $(\leq 1$ $\mathrm{L} / \mathrm{min}$ ) could be considered as an effective way to alleviate hypothermia for the neonates undergoing digestive surgery. Intraoperatively low fresh gas flow was 
independently associated with the occurrence of hypothermia.

Ethic approval and consent to participate Our study was approved by Institutional Review Board (IRB) at Chengdu Women's and Children's Central Hospital. After obtaining Institutional Review Board (IRB) approval [No. 2020(3)], we retrieved patient data from the electrical record system at Chengdu Women's and Children's Central Hospital.

\section{Supplementary information}

Supplementary information accompanies this paper at https://doi.org/10. 1186/s12871-020-01140-5.

\section{Additional file 1.}

\section{Abbreviations}

PLOS: Postoperative hospital length-of- stay; IRB: Institutional Review Board; SD: Standard deviation; IQR: Interquartile range

\section{Authors' contributions}

YC: Data collection, original draft writing, conceptualization, and draft writing. YW: Conceptualization and original draft writing. RC: Original draft writing, conceptualization, and draft writing. GL: Statistical analysis. LMD: Data collection. JL: Data collection. All authors read and approved the final manuscript.

\section{Funding}

This research did not receive any specific grant from funding agencies in the public, commercial, or not-for-profit sectors.

\section{Availability of data and materials}

The datasets used and/or analysed during the current study available from the corresponding author on reasonable request.

\section{Consent for publication}

Not applicable.

\section{Competing interests}

The authors declare no competing interests.

\section{Author details}

${ }^{1}$ Department of Anesthesiology, The Affiliated Hospital, School of Medicine, UESTC Chengdu Women's \& Children's Central Hospital, No.1617, Riyue Avenue, Qingyang District, Chengdu 610091, PR China. ${ }^{2}$ Department of Anesthesilogy, No.363 hospital, Chengdu 610041, China. ${ }^{3}$ Department of Anesthesiology, Vanderbilt University Medical Center, Nashville, TN 37232, USA.

Received: 9 May 2020 Accepted: 26 August 2020

Published online: 03 September 2020

\section{References}

1. Blum R, Cote C. Pediatric equipment. In: Blum R, Cote C, editors. A practice of Anaesthesia for infants and children. Philadelphia: Saunders Elsevier; 2009. p. 1099-101.

2. Sessler D. Temperature disturbances. In: Sessler D, editor. Pediatric anesthesia. Philadelphia: Churchill Livingstone; 2002. p. 53-84.

3. Moslemi-Kebria M, El-Nashar SA, Aletti GD, Cliby WA. Intraoperative hypothermia during cytoreductive surgery for ovarian cancer and perioperative morbidity. Obstet Gynecol. 2012;119:590-6.

4. Lai LL, See MH, Rampal S, Ng KS, Chan L. Significant factors influencing inadvertent hypothermia in pediatric anesthesia. J Clin Monit Comput. 2019; 33:1105-12.
5. Horosz B, Malec-Milewska M. Methods to prevent intraoperative hypothermia. Anaesthesiol Intensive Ther. 2014;46:96-100.

6. Bilgi M, Goksu S, Mizrak A, Cevik C, Gul R, Koruk S, Sahin L. Comparison of the effects of low-flow and high flow inhalational anaesthesia with nitrous oxide and desflurane on mucociliary activity and pulmonary function tests. Eur J Anaesthesiol. 2011;28:279-83.

7. Kleemann PP. Humidity of anaesthetic gases with respect to low flow anaesthesia. Anaesth Intensive Care. 1994;22:396-408.

8. Keller KA, Callan C, Prokocimer P, Delgado-Herrera L, Friedman MB, Hoffman GM, Wooding WL, Cusick PK, Krasula RW. Inhalation toxicity study of a haloalkene degradant of sevoflurane, compound a (PIFE), in SpraqueDawley rats. Anesthesiology. 1995;83:1220-32.

9. Patel N, Maguire D, Dexter F, Epstein RH. Reduction of fresh gas flow during administration of volatile anesthetic agents via monthly individualized email feedback: Annual Meeting of the Society for Technology in Anesthesia; 2014. Available at: http://www.stahq.org/files/7013/9171/8017/13_ Abstract_ Epstein.pdf. Accessed January 3, 2015

10. Obata R, Bito H, Ohmura M, Moriwaki G, Ikeuchi Y, Katoh T, Sato S. The effects of prolonged low-flow sevoflurane anesthesia on renal and hepatic function. Anesth Analg. 2000;91:1262-8.

11. Lo C, Ormond G, McDougall R, Sheppard SJ, Davidson AJ. Effect of magnetic resonance imaging on core body temperature in anaesthetised children. Anaesth Intensive Care. 2014;42:333-9.

12. Engorn BM, Kahntroff SL, Frank KM, Singh S, Harvey HA, Barkulis CT, Barnett AM, Olambiwonnu OO, Heitmiller ES, Greenberg RS. Perioperative hypothermia in neonatal intensive care unit patients: effectiveness of a thermoregulation intervention and associated risk factors. Paediatr Anaesth. 2017;27:196-204.

13. National Institute for Health and Care Excellence. Inadvertent perioperative hypothermia: the management of inadvertent perioperative hypothermia in adults [CG65]. London: National Institute for Health and Care Excellence [UK]; 2016. https ://www. nice.org.uk/guida nce/cg65.

14. Kongsayreepong S, Chaibundit C, Chadpaibool J, Komoltri C, Suraseranivongse S, Suwannanonda P, Raksamanee EO, Noocharoen P, Silapadech A, Parakkamodom S, Pum-In C, Sojeoyya L. Predictor of core hypothermia and the surgical intensive care unit. Anesth Analg. 2003;96: 826-33.

15. de Castro J Jr, Bolfi F, de Carvalho LR, Braz JR. The temperature and humidity in a low-flow anesthesia workstation with and without a heat and moisture exchanger. Anesth Analg. 2011;113:534-8.

16. Bicalho GP, Braz LG, de Jesus LS, Pedigone CM, de Carvalho LR, Módolo NS, Braz JR. The humidity in a Dräger primus anesthesia workstation using low or high fresh gas flow and with or without a heat and moisture exchanger in pediatric patients. Anesth Analg. 2014;119:926-31.

17. Frank SM, Fleisher LA, Breslow MJ, Higgins MS, Olson KF, Kelly S, Beattie C. Perioperative maintenance of normothermia reduces the incidence of morbid cardiac events. A randomized clinical trial. JAMA. 1997;277:1127-34.

18. Kurz A, Sessler DI, Lenhardt $R$. Perioperative normothermia to reduce the incidence of surgical-wound infection and shorten hospitalization. Study of wound infection and temperature group. N Engl J Med. 1996;334:1209-15.

\section{Publisher's Note}

Springer Nature remains neutral with regard to jurisdictional claims in published maps and institutional affiliations.

Ready to submit your research? Choose BMC and benefit from:

- fast, convenient online submission

- thorough peer review by experienced researchers in your field

- rapid publication on acceptance

- support for research data, including large and complex data types

- gold Open Access which fosters wider collaboration and increased citations

- maximum visibility for your research: over $100 \mathrm{M}$ website views per year

At BMC, research is always in progress.

Learn more biomedcentral.com/submission 